\title{
ENSEÑANZAS DE LA CRISIS FINANCIERA PARA LA ESTABILIDAD PRESUPUESTARIA Y EL CONTROL DEL SECTOR PÚBLICO
}

\author{
Lessons from the Financial Crisis to the Budgetary \\ Stability and Control of the Public Sector
}

CARLOS MONASTERIO ESCUDERO

\section{RESUMEN}

La crisis financiera iniciada en septiembre de 2008 ha coincidido en el tiempo con un proceso de déficit y endeudamiento público crecientes, en buena medida originado por los cuantiosos fondos que han debido dedicarse al saneamiento y recapitalización del sector financiero.

Ante los problemas suscitados por la crisis financiera, se han desplegado una serie de iniciativas de reforma, tanto internacionales, en el Banco Internacional de Pagos de Basilea, que aprobó el paquete de reformas conocido como «Basilea III», como a escala europea, con importantes reformas en materia de solvencia bancaria y mejora del gobierno interno de las entidades. La mayor rapidez de las reformas instrumentadas en el sector financiero permite aprovechar la experiencia comparada de los supervisores y reguladores financieros para revisar los mecanismos de control del Sector Público, especialmente en lo relativo al control de eficiencia, donde una mayor atención al papel jugado por los conflictos de intereses y los incentivos de los órganos de control podría mejorar la gobernanza y el grado de control, haciéndolo más operativo. De este modo, podría conseguirse una mejora en el grado de consecución de los principios constitucionales de estabilidad presupuestaria y eficiencia del gasto, adoptando una metodología renovada y actual, para su implementación.

PALABRAS CLAVE: eficiencia del gasto; estabilidad presupuestaria; control del sector público. 


\section{ABSTRACT}

The financial crisis that started in September 2008 has coincided with an increasing deficit and public debt process, largely caused by the need to dedicate significant financial support, in order to restore health to the financial sector and recapitalize it.

Given the problems raised by the financial crisis, a set of reform initiatives have been developed: internationally, the Bank for International Settlements approved the reform package known as Basel III; in the European frame, significant reforms in banking solvency and in improving the internal bank governance have been applied.

The swiftness of the reforms implemented in the financial sector allows to take advantage of the comparative experience of supervisors and regulators to review financial control mechanisms in the Public Sector, especially regarding efficiency control, where greater attention to the role played by the conflicts of interest and incentives for the supervisory bodies could improve governance and the degree of control, making it more operative.

In this way an improvement in the degree of achievement of the constitutional principles of fiscal sustainability and efficiency of expenditure could be achieved, adopting a modern and renewed methodology for its implementation.

KEY WORDS: expenditure efficiency; budget stability; public sector control.

I INTRODUCCIÓN.- -II. LA CRISIS FINANCIERA Y SUS CONSECUENCIAS EN ESPAÑA.III. LA ESTRATEGIA DE REFORMA DE LA SUPERVISIÓN FINANCIERA.-IV. LAS LECCIONES DE LA EXPERIENCIA COMPARADA.-V. CONCLUSIONES.-BIBLIOGRAFÍA.

\section{INTRODUCCIÓN}

Tras la reforma de septiembre de 2011, que modificó el artículo 135 de la Constitución Española (CE), consagrando el principio de estabilidad presupuestaria como uno de los principios rectores de la actuación económica del Sector Público español en materia presupuestaria, se ha tendido a interpretar dicho principio de manera reduccionista y a entenderlo fundamentalmente como un criterio contable, aplicado al proceso presupuestario.

En este sentido, una gran parte de análisis y comentarios entienden que lo que establece el artículo $135 \mathrm{CE}$ es la obligación de respetar un valor máximo para el déficit público, medido éste en términos de Necesidad/Capacidad de 
Financiación, que es el concepto de déficit utilizado en el Protocolo de Déficit Excesivo (PDE) de la Unión Europea (UE).

También este enfoque reduccionista supone, implícitamente, que los peligros para la sostenibilidad presupuestaria proceden fundamentalmente de dentro del Sector Público, debido a algún tipo de disfunciones en el proceso presupuestario, sin tener en cuenta que la inestabilidad presupuestaria puede tener su origen fuera del ámbito del Sector Público, concretamente en problemas graves del sector financiero, que posteriormente desembocan en graves problemas de déficit público y finalmente, en el rescate del país por parte de la UE, como muestran los recientes casos de Irlanda y España.

Sin embargo, en un ejercicio de análisis económico de los principios constitucionales, entendemos que la interpretación correcta del principio de estabilidad presupuestaria exige adoptar una perspectiva amplia e interpretar conjuntamente los artículos 135, 31.2 y 149.1.11. a , si se quiere entender cabalmente todo el alcance de la estabilidad presupuestaria.

En primer lugar, si contemplamos en sentido amplio la estabilidad presupuestaria, la existencia de sectores de gran peso económico, como es el caso del sector financiero (que en algunos países excede del tamaño del PIB nacional), junto al hecho de que existen entidades de tamaño demasiado grande para quebrar (el fenómeno conocido como «too big to fail»), por sus efectos perturbadores sobre la continuidad de los sistemas de pagos y la seguridad de los depositantes, hacen que la supervisión eficiente de estos sectores sea un ingrediente esencial de la estabilidad presupuestaria, como ha demostrado el caso de Irlanda, donde las ayudas a la banca forzaron el rescate del país, o en menor medida el de España, donde la solicitud de ayuda financiera en julio de 2012 probablemente evitó el rescate, a costa de aceptar la condicionalidad en la reforma del sistema financiero. Vemos que en ambos casos la estabilidad presupuestaria fue quebrada por sucesos ocurridos fuera del Sector Público, que tienen que ver con una adecuada regulación del sistema financiero y bancario, que es una competencia exclusiva del Estado, según establece el artículo 149.1.11. ${ }^{\text {a }} \mathrm{CE}$.

La importancia de este enfoque es reconocida por el Tribunal de Cuentas Europeo, que se ha planteado la necesidad de realizar una auditoría financiera y de gestión de los diversos supervisores financieros (Tribunal de Cuentas Europeo, 2011).

En la misma dirección que lo anterior, el hecho de que la calidad de la regulación del sector financiero sea mayor en los países de mayor nivel de renta y desarrollo y que éstos dediquen más recursos a la actividad supervisora (Cihak y Tieman, 2008), parece avalar la importancia creciente de mejorar la eficiencia regulatoria y supervisora, para asegurar así la estabilidad presupuestaria. 
En el período más reciente, la crisis financiera iniciada con la quiebra de Lehman Brothers en septiembre de 2008 ha dado lugar a una profunda reestructuración del sector financiero, que ha supuesto un vuelco importante en la regulación pública de este sector. Valorar adecuadamente el alcance de dichos cambios regulatorios es esencial, para reforzar la estabilidad presupuestaria.

En segundo lugar, la estabilidad presupuestaria proclamada en el artículo $135 \mathrm{CE}$ debe contemplarse en el marco del proceso presupuestario entendido en sentido amplio, del cual es un ingrediente esencial la programación eficiente del gasto.

En este sentido, el clásico principio de eficiencia en la programación y control del gasto público, recogido en el artículo $31.2 \mathrm{CE}$, ha sido relativamente relegado en la práctica presupuestaria debido, por un lado, a la tradicional preeminencia del principio de legalidad y, por otro, a que la eficiencia del gasto se ha entendido en un sentido restrictivo, aplicando unos criterios que eran los propios del momento en que se aprobó la $\mathrm{CE}$, pero que en estos momentos no tiene en cuenta los nuevos y más amplios enfoques del control de eficiencia y la interrelación de este principio con el de estabilidad presupuestaria.

En la concepción tradicional, se entiende la eficiencia como el modo de alcanzar un objetivo determinado al mínimo coste posible, lo cual implica en la práctica el identificar las unidades más eficientes mediante alguna técnica (normalmente, análisis envolvente de datos) y medir luego las potenciales ganancias del resto de unidades productivas, bien con medidas de eficiencia orientadas al input (cuantos recursos podrían ahorrar, manteniendo el mismo nivel del output) o al output (manteniendo como dados los input, cuanta mayor cantidad de output podría obtenerse).

Esta concepción de la eficiencia se refiere a programas de gasto y utiliza medidas de input y output para optimizar la gestión presupuestaria. Sin embargo, una visión más amplia de la eficiencia debe abarcar también el análisis de las actividades regulatorias, que son una parte esencial de la actuación del Sector Público y utilizar otros criterios de análisis, de tipo cualitativo, para asegurar un buen gobierno interno de las entidades y la correcta gestión de los conflictos de intereses.

De otro modo, estaríamos dejando al margen del control de eficiencia importantes aspectos que influyen en la toma de decisiones y que determinan, en última instancia, el consumo de recursos y los resultados de los programas de gasto y regulatorios.

Otro nexo de unión entre crisis financiera y crisis del Sector Público viene dado porque alguno de los problemas de fondo en ambos sectores es común y 
tiene que ver, en última instancia, con el control de eficiencia, entendido éste en sentido amplio.

En el sector financiero el funcionamiento eficiente de las entidades asegura su rentabilidad, que es el único modo seguro de garantizar su solvencia, puesto que las inyecciones puntuales de capital no pueden resolver permanentemente el problema de bancos que no sean rentables.

En el caso del Sector Público, la eficiencia del gasto es un requisito necesario en todo momento, pero se vuelve especialmente valioso en momentos de crisis, donde las restricciones al déficit hacen más necesario aprovechar al máximo los recursos públicos.

El objetivo de este trabajo es analizar el desarrollo de la crisis financiera, con énfasis especial en las iniciativas de reforma, que en España y en la Unión Europea han cristalizado recientemente en la aplicación paulatina de la Unión Bancaria, cuyo primer eslabón, el Mecanismo Único de Supervisión bancaria (MUS), ha entrado en vigor el pasado 4 de noviembre de 2014.

La base normativa para el funcionamiento del MUS son el Reglamento núm. 1024/2013 y el Reglamento marco núm. 468/2014, ambos del Banco Central Europeo (BCE).

La homogeneización del procedimiento supervisor, para las entidades significativas de la U.E, ha ido acompañada de avances en paralelo, para la creación de un Mecanismo Único de Resolución Bancaria (MUR), en el que se concreta el modo en que deben absorberse por los accionistas y titulares de deuda de una entidad las pérdidas de ésta, antes de que pueda apelarse a los fondos públicos. El MUR está regulado en la Directiva 2014/59/UE y el Reglamento 806/2014.

La estructura del trabajo es la siguiente; en el apartado II, examinaremos los orígenes de la crisis financiera y el modo en que el Sector Público español ha llevado a cabo la supervisión, regulación y control del sistema financiero y las ayudas públicas comprometidas en su rescate. El siguiente apartado se ocupa de las distintas iniciativas de reforma que se han formulado respecto al sistema financiero, cuyas crisis se ha desarrollado de modo más acelerado en el tiempo que la del Sector Público y en el cual las respuestas han sido también más rápidas.

El apartado IV partiendo de la experiencia comparada de la crisis financiera, analiza en qué modo ésta puede ser utilizada para mejorar el control de eficiencia y el gobierno interno en el Sector Público.

Cierra el trabajo un breve apartado de conclusiones. 


\section{LA CRISIS FINANCIERA Y SUS CONSECUENCIAS EN ESPAÑA}

Las profundas consecuencias de la crisis financiera iniciada en septiembre de 2008 fueron de dos tipos.

En un primer momento, los Bancos Centrales, como supervisores del sistema financiero, en muchos casos junto con los Tesoros nacionales, adoptaron medidas de recapitalización de las entidades con problemas de solvencia (debido al deterioro de la calidad del balance) y también mecanismos extraordinarios de provisión de liquidez, que compensaran la brusca desaparición del mercado interbancario.

Además de lo anterior, en la Unión Europea varios países (España entre ellos) incrementaron el importe de los depósitos cubiertos por el Fondo de Garantía de Depósitos (FGD), tratando de evitar un pánico financiero de los depositantes, que agravase los problemas de liquidez de las entidades.

Una importante constatación en la U.E, aparte de la elevación unilateral del límite cubierto por el FGD, fue que los bancos que tenían dimensión europea y operaban en varios países, eran «europeos en tiempos normales y nacionales en tiempos de crisis», puesto que, en caso de problemas, la inyección de fondos públicos y su reestructuración, corrían a cargo del país de origen. Unido a lo anterior, está el hecho de que estas reacciones inmediatas ante la crisis obligaron a interpretar en sentido amplio la normativa europea sobre ayudas públicas distorsionadoras de la competencia, entendiendo que existía un supuesto de grave crisis económica, que exceptuaba a las medidas públicas de ayuda y las declaraba compatibles.

En las primeras respuestas a la crisis de los supervisores nacionales, se pudo apreciar una inadecuada coordinación, tanto en lo que respecta a la coordinación entre los diversos supervisores nacionales (bancario, de mercados de valores y de seguros), como por la carencia de un esquema común de supervisión entre países. Cada país reaccionó de forma pragmática, según las características de los bancos nacionales afectados (Larossière, 2009, pág. 12), pero la ausencia de una estrategia europea para enfrentar la crisis financiera fue evidente, en la fase inicial.

Relacionado con lo anterior, está el hecho de que los países europeos que intervinieron desde el primer momento (Maudos, 2013, págs. 122-126), inyectando cuantiosas ayudas en su sistema financiero (Irlanda, Luxemburgo, Grecia, Holanda, Bélgica, Reino Unido) lo hicieron sin restricciones externas y sin tener que asumir compromisos posteriores. Por el contrario, en España las medidas iniciales fueron más tímidas, confiando en que las llamadas «provisio- 
nes dinámicas» (provisiones de insolvencias ligadas al aumento del crédito y no asignadas de modo específico a créditos concretos) (Turner, 2009, pág. 63) fueran suficientes para afrontar el problema, lo cual se reveló posteriormente erróneo.

En todo caso, tanto la experiencia de las crisis precedentes en el sistema financiero mundial (Reinhardt y Rogoff, 2009, págs. 141-171), como las ayudas públicas empleadas en la actual crisis, revelan que normalmente, cuando puede evaluarse el coste neto de las intervenciones públicas (fondos inyectados para la reestructuración bancaria, minorados en las cantidades devueltas por los bancos o procedentes de privatización de entidades nacionalizadas) para sostener al sistema financiero de un país, el importe es muy elevado, en relación al PIB (Furceri y Mourougane, 2009, págs. 27-29).

En el caso de España, a los supervisores tradicionales del sistema financiero, Banco de España (BdE) y Comisión Nacional del Mercado de Valores (CNMV), se añadió, en primer lugar, el Fondo para la Adquisición de Activos Financieros (FAAF), con el objetivo de proporcionar liquidez a las entidades. Posteriormente, los problemas específicos de gestionar a las entidades inmersas en procesos de reestructuración (que son de una naturaleza muy distinta a los habituales procesos de supervisión) condujeron a la creación del Fondo de Reestructuración Ordenada Bancaria (FROB). Finalmente, el saneamiento de los balances de las entidades en proceso de reestructuración llevó a la creación de la Sociedad de Gestión de Activos procedentes de la Reestructuración Bancaria (SAREB), que recibió los activos inmobiliarios procedentes de las entidades reestructuradas con ayudas públicas (1).

Cronológicamente, la primera entidad intervenida en España, como consecuencia de la crisis financiera, fue la Caja de Ahorros de Castilla-La Mancha (CCM), el 28 de marzo de 2009, por decisión de la Comisión Ejecutiva del Banco de España y en aplicación de la Ley 26/1988, de Disciplina e Intervención de Entidades de Crédito. Los apoyos financieros necesarios se canalizaron a través del BdE y del Fondo de Garantía de Depósitos en Cajas de Ahorros (FGDCA).

La experiencia de la intervención de CCM mostró que los mecanismos de supervisión tradicionales presentaban limitaciones de cara a la tarea de gestionar, posteriormente a su intervención, entidades en crisis y que había también problemas de gobernanza, al tener que actuar con los mismos órganos de gobierno (Asamblea General de CCM), hasta la disolución de la entidad.

(1) Los apartados 21 y 22 del MoU establecen el tipo de entidades y las clases de activos que debían ser traspasados a SAREB.

Revista Española de Derecho Constitucional

ISSN-L: 0211-5743, núm. 105, septiembre-diciembre (2015), págs. 51-76

http://dx.doi.org/10.18042/cepc/redc.105.02 
El Real Decreto-ley 9/2009, sobre reestructuración ordenada bancaria, creó el FROB, como instrumento para apoyar la solvencia de entidades con problemas o que deseaban reforzar su solvencia. Desde su creación, el FROB ha sido la institución que ha gestionado los diversos planes de reestructuración bancaria en España (2).

Debido al hecho de que, en gran medida, los problemas de las entidades en materia de solvencia se debían a la elevada exposición a los activos inmobiliarios en sus balances (en especial, crédito promotor y constructor), diversas actuaciones normativas, entre las que destacan el Real Decretoley $2 / 2011$, de reforzamiento del sistema financiero y el Real Decreto-ley $2 / 2012$, de saneamiento del sector financiero, aumentaron las provisiones y coberturas de este tipo de activos, para reforzar la solvencia de las entidades más expuestas.

Paralelamente, ante el temor de que los depositantes pudieran verse afectados por las dudas sobre la solvencia de las entidades financieras y se iniciara un proceso de retirada masiva de depósitos, se elevó el límite de la garantía cubierta en los depósitos, hasta los 100.000 euros. Posteriormente, el Real Decreto-ley 16/2011 creó el FGDEC, quedando suprimida la anterior regulación, en la que estaban separados los tres FGD correspondientes a Cajas de Ahorros, Bancos y Cooperativas de Crédito.

El diseño concreto de la etapa crucial de la reestructuración financiera en España arranca de la solicitud de asistencia financiera a la Unión Europea, en junio de 2012, que condujo a la firma, el 23 de julio de 2012, del Memorándum de Entendimiento $(\mathrm{MoU})$ sobre condiciones de política sectorial financiera.

El MoU es el documento clave para entender el proceso de reestructuración financiera en España y su desarrollo normativo se ha plasmado en la Ley 9/2012, de 14 de noviembre, de reestructuración y resolución de entidades de crédito (3) y el Real Decreto 1559/2012, de 15 de noviembre, que crea la Sociedad de Gestión de Activos Procedentes de la Reestructuración Bancaria (SAREB), a la que se transfirieron los activos inmobiliarios de las entidades con planes de reestructuración.

En el proceso en marcha de Unión Bancaria europea, el FROB está relacionado con las funciones del Mecanismo Único de Resolución (MUR) y el FGDEC está conectado con el futuro fondo europeo de garantía de depósitos.

(2) La regulación del funcionamiento del FROB ha sido modificada posteriormente en diversas ocasiones y su normativa actual viene recogida en la Ley 9/2012.

(3) Promulgado inicialmente como Real Decreto-ley 24/2012. 
Tras la intervención de diversas entidades por parte del FROB, cuando en 2012 se firmó el Memorando de Entendimiento sobre condiciones de política sectorial financiera (MoU, 2012), todo el proceso subsiguiente de reestructuración financiera quedó sujeto al cumplimiento de condiciones estrictas que originaron, entre otras consecuencias, que los titulares de instrumentos híbridos de capital (participaciones preferentes y deuda subordinada) tuvieran que asumir obligatoriamente parte del coste de la reestructuración, con el fuerte impacto social que es bien conocido.

Un hecho llamativo en España es que la crisis se centró, de modo casi exclusivo, en el sector de las cajas de ahorros, debido a un doble motivo. En primer lugar, en momentos de problemas de solvencia y con exigencia de obtener a corto plazo importantes volúmenes de capital, estas entidades, que no podían acudir al mercado a través de ampliaciones, tenían un grave hándicap (Serra, 2011, págs. 59-69). En segundo lugar, los problemas de falta de profesionalidad y deficiente gobierno interno de este tipo de entidades, agravaron el problema anterior, dado que su fuerte exposición al sector inmobiliario había deteriorado fuertemente su balance, originando necesidades de capital comparativamente mayores (Maudos, 2013, págs. 151-156).

Adicionalmente, la distribución de competencias entre el supervisor principal, BdE y las CCAA, que gozaban de ciertas competencias en materia de designación y control de órganos de gobierno, condujo probablemente a cierto abandono del control de la gobernanza interna, buena muestra del cual podemos ver en uno de los pocos informes de los Órganos de Control Externos (OCEx) territoriales (Cámara de Comptos de Navarra, 2014). Como señala el documento citado, la nula actividad supervisora de la Comunidad, durante un período tan dilatado como 1982-2011 (Cámara de Comptos, 2014, págs. 22-23), unido al defecto capital de que quien designaba a los miembros clave de los órganos de gobierno fuera, a la vez, el responsable de su control (Cámara de Comptos, 2014, págs. 21 y 26), originaron una inefectividad de los controles, en la práctica.

Hay que mencionar que, de modo sintético, la supervisión y control de las entidades financieras, tanto bancos como cajas de ahorros, depende principalmente del Banco de España y, en menor medida, de la Comisión Nacional del Mercado de Valores, en cuanto emisoras en los mercados de capitales y prestadoras de servicios de inversión (recepción y ejecución de órdenes y comercializadoras de productos de inversión).

El abanico de competencias de que goza el supervisor principal, BdE, es amplio y consiste principalmente en: 
- Autorización para operar como entidad de crédito (4).

- Evaluar la idoneidad de los miembros del órgano de gobierno y personas que ocupan puestos clave en la entidad, respecto a la determinación de su perfil global de riesgo.

- Autorización de la adquisición de participaciones significativas.

- Solicitar información reservada periódica sobre la situación económica y financiera y requerimiento de datos puntuales.

- Realización de inspecciones in situ.

- Formular requerimientos, para subsanar deficiencias detectadas por la inspección, fijando condiciones y plazos para su cumplimiento.

- Apertura de procedimientos sancionadores, cuando la gravedad de las deficiencias detectadas por la inspección así lo aconseje.

- Imposición de sanciones por la comisión de infracciones leves, graves o muy graves [en el caso de estas últimas, puede llegar a la revocación de la autorización para operar como entidad de crédito (5)].

Como se ha comentado, en el transcurso de la crisis financiera, se fueron creando nuevos organismos públicos que se ocuparon de tareas que, los supervisores tradicionales (BdE y CNMV) no estaban preparados para desarrollar, puesto que tenían más relación con actuaciones de prevención o gestión de entidades en crisis que con las actividades propias de la supervisión.

Respecto a los fondos públicos comprometidos, la complejidad de la crisis financiera y los distintos avatares de ésta han hecho que las ayudas públicas comprometidas en apoyos de liquidez y solvencia a las entidades hayan sido de diverso tipo, con una cuantificación final que no puede hacerse con precisión en este momento, dado que está pendiente la privatización de una serie de entidades, que permitirá recuperar parte de las ayudas y que otros apoyos públicos, como la cobertura de posibles pérdidas de ciertas carteras (los llamados Esquemas de Protección de Activos, EPA), dependerán finalmente de en qué medida estén dañados los activos incluidos en carteras EPA, lo cual no se conocerá con exactitud hasta 2021-2022, en que acaba la vigencia de los EPA de UNNIM,

(4) Hasta la promulgación de la Ley 10/2014, de 26 de junio, la concesión de la ficha bancaria correspondía al Ministerio de Economía, previo informe favorable del BdE, CNMV y Servicio Ejecutivo para la Prevención del Blanqueo de Capitales (SEPBLAC).

(5) Hasta la promulgación de la Ley 10/2014, la imposición de sanciones por infracciones muy graves correspondía al Ministro de Economía y Hacienda, salvo que supusieran la pérdida de la autorización para operar como entidad de crédito, en cuyo caso correspondían al Consejo de Ministros, según lo dispuesto en el artículo 18 de la Ley 26/1988, de Disciplina e Intervención de Entidades de Crédito. 
Banco CAM y Banco de Valencia (Tribunal de Cuentas, 2013.b, págs. 20-28; Banco de España, 2014 y 2015; FROB, 2014).

Teniendo en cuenta que algunos instrumentos de apoyo han completado su ciclo, como el Fondo de Adquisición de Activos Financieros (FAAF), que puso a disposición de las entidades financieras recursos cercanos a los 20.000 millones de $€$, generando un resultado neto positivo para el Tesoro de 249,5 millones de $€$ (Tribunal de Cuentas, 2013.a, pág. 55), podemos comprobar cómo estas ayudas de liquidez no han supuesto coste para el contribuyente.

En el caso de los avales públicos a las emisiones de entidades privadas, su importe total asciende a 110.895 millones de $€$, habiéndose cancelado, a 21 de abril de 2015, un importe de 105.641 millones de $€$, el 95 por 100 del total, no estando prevista ninguna pérdida derivada de este tipo de apoyos (Banco de España, 2015, pág. 2).

El grueso de las ayudas públicas que pueden suponer un coste neto para el contribuyente son las que tienen como finalidad el refuerzo de la solvencia de las entidades, instrumentadas bien mediante aportación de recursos computables como capital o mediante la garantía de cobertura de pérdidas de las carteras EPA.

También hay que mencionar que, al margen del sector bancario, pero relacionado con el saneamiento de activos inmobiliarios de entidades financieras reestructuradas, a 28 de febrero de 2015, el FROB había aportado al capital de SAREB fondos públicos por 2.192 millones de $€$, además de avales públicos a la deuda emitida por SAREB, por un importe de 45.028 millones de $€$ (Banco de España, 2015, pág. 3).

\section{CUADRO 1}

Principales ayudas públicas en el proceso de reestructuración financiera en España (millones de €)

\begin{tabular}{|l|c|c|}
\hline \multicolumn{1}{|c|}{ Grupo } & $\begin{array}{c}\text { Ayudas en forma } \\
\text { de capital }\end{array}$ & $\begin{array}{c}\text { Esquemas de protección } \\
\text { de activos } \\
\text { (EPAs) }\end{array}$ \\
\hline Banca Cívica & 977 & 4.366 \\
\hline Banco de Valencia & 5.498 & 4.824 \\
\hline UNNIM & 953 & \\
\hline Caja 3 & 407 & 16.610 \\
\hline Banco CAM & 5.249 & \\
\hline Banco Gallego & 245 & \\
\hline
\end{tabular}




\begin{tabular}{|l|c|c|}
\hline \multicolumn{1}{|c|}{ Grupo } & $\begin{array}{c}\text { Ayudas en forma } \\
\text { de capital }\end{array}$ & $\begin{array}{c}\text { Esquemas de protección } \\
\text { de activos } \\
\text { (EPAs) }\end{array}$ \\
\hline Banco CEISS & 1.129 & 2.475 \\
\hline CCM & 1.740 & \\
\hline Liberbank & 124 & \\
\hline BMN & 1.645 & \\
\hline BFA-Bankia & 22.424 & 392 \\
\hline NCG Banco & 9.052 & $28.667(* *)$ \\
\hline Catalunya Banc & 12.052 & \\
\hline Cajasur & & \\
\hline Total & $61.495(*)$ & \\
\hline
\end{tabular}

Fuente: Elaboración propia, a partir de los datos de BdE y Tribunal de Cuentas.

(*) De esta cantidad se han recuperado 2.666 millones, hasta mayo 2015.

(**) Esa cifra es el importe máximo cubierto por los EPAs, que sería la pérdida total máxima teórica; la pérdida máxima esperada a 31 de diciembre de 2014 alcanzaba, en términos nominales, 9.581 millones de $€$ ( 9.215 millones de $€$, en valor presente).

El juicio del Tribunal de Cuentas, tras la fiscalización del FAAF, señala que en su diseño y justificación no se evalúan las razones que llevaron a optar por un instrumento de esta naturaleza, ni tampoco se examinan las alternativas de intervención, haciendo un análisis comparado entre las distintas opciones (Tribunal de Cuentas, 2013.a, pág. 54).

Respecto a la fiscalización del FROB y el FGDEC, es de lamentar que la óptica de la misma haya sido reducida a un mero control de legalidad, dejando explícitamente fuera «otros posibles objetivos, como la oportunidad económico-financiera de las decisiones adoptadas o la eficacia de tales decisiones» (Tribunal de Cuentas, 2013.b, pág. 10).

\section{LA ESTRATEGIA DE REFORMA DE LA SUPERVISIÓN FINANCIERA}

Desde el principio de la crisis financiera, además de las diversas medidas de política económica para sostener y reestructurar las entidades en crisis, se realizaron diversos análisis, normalmente por comisiones de expertos, para tratar de averiguar qué había ido mal, cuáles eran los orígenes de la crisis y, en consecuencia, cuáles serían los aspectos clave de una estrategia reformadora para darles respuesta. 
Aunque son múltiples los documentos que contienen aportaciones de interés hay varios informes generales que destacan por la calidad de sus análisis, por abordar el tema desde una perspectiva global y por el impacto que han tenido sobre las reformas posteriores.

Las profundas consecuencias de la crisis financiera llevaron a que la Financial Services Authority (FSA) revisara en profundidad los fallos de los reguladores y supervisores, en el conocido como Informe Turner (Turner, 2009). Una de las más importantes constataciones de este informe es que la innovación financiera (titulizaciones) y el apalancamiento creciente llevaron a minusvalorar el riesgo global asumido por el sistema financiero, debido en buena medida a que los modelos internos para medir el riesgo de crédito (usados especialmente por los grandes bancos multinacionales) minusvaloraban el riesgo sistémico, sin advertir que las crisis de una entidad se trasladan con rapidez al conjunto, en el caso del sistema financiero (Turner, 2009; págs. 22 y 44-45).

Como resultante, la creencia en la disciplina del mercado como instrumentos de autorregulación financiera, se extendió de modo inadecuado, creando una sensación de falsa seguridad, que no sólo afectó a los agentes del mercado, sino que acabó siendo asumida también por el regulador. Un peligro adicional procedía de la extensión de la «banca en la sombra» y de la proliferación de instrumentos financieros no regulados, fuera del control de los supervisores, olvidando que lo esencial de la regulación sería atender a la naturaleza económica de los riesgos subyacentes y no a su forma legal (Turner, 2009, pág. 72). Se produjo así una proliferación de mecanismos de elusión financiera, desarrollada en buena medida por los principales bancos, que prestaban servicios similares a los financieros, pero desde instituciones no reguladas ni supervisadas.

Casi simultáneamente con el Informe Turner, la Unión Europea hizo público el conocido como Informe Larossière, que tomó su nombre del presidente del Grupo de trabajo de alto nivel, creado para revisar el funcionamiento de la supervisión financiera en Europa (Larossière, 2009).

Las conclusiones del Informe Larossière coinciden, en buena media con las del Informe Turner, al señalar a la «banca en la sombra» como uno de los peligros, al debilitar el perímetro de control, si bien señala también con cierta amplitud el papel jugado por las deficiencias en los mecanismos de gobernanza interna de las entidades (escasa atención a los conflictos de intereses, formación inadecuada de los órganos de gobierno y control y excesiva confianza en el paradigma del mercado autorregulado) y al efecto perverso de ligar las remuneraciones variables de la alta dirección a objetivos de rentabilidad medidos a corto plazo, sin tener en cuenta los efectos sobre el nivel de riesgo y solvencia a medio y largo plazo (Larossière, 2009, págs. 8-10). 
Otra importante constatación del Informe Larossière es la prociclícidad a que lleva la regulación de Basilea II, que contribuye a amplificar el efectos de las perturbaciones económicas, una vez que éstas han aparecido (Larossière, 2009, págs. 17 y 19).

Posterior a los informes citados es el de la Comisión de Investigación del Sector Bancario de Irlanda, que rindió su informe en marzo de 2011. Seguramente por el fuerte impacto que tuvo la crisis bancaria en Irlanda, que forzó finalmente el rescate del país, este informe supone un análisis muy profundo de las causas de la crisis, distinguiendo entre las responsabilidades de los órganos de gobierno y dirección de los bancos, el papel jugado por los auditores externos y, finalmente, las actuaciones (y omisiones) de las autoridades reguladoras y supervisoras.

Un rasgo común del caso irlandés con el español, es el profundo arraigo que llegó a cobrar lo que el informe llama la «manía especulativa nacional», basada en la creencia irracional de que el valor real de las propiedades inmobiliarias no puede caer y que, en consecuencia, siempre pueden obtenerse ganancias de capital adquiriendo activos inmobiliarios. Si es preocupante que en los inversores arraigue esta creencia, lo es mucho más que sea compartida por los órganos de gobierno de las grandes entidades financieras y que el supervisor nacional no advierta de la irracionalidad de la creencia.

En Irlanda, como en España, crecieron en paralelo la burbuja crediticia y la inmobiliaria, apoyada la primera en la notable caída de los tipos de interés que siguió a la entrada en la eurozona y a la facilidad para obtener financiación abundante en los mercados mayoristas interbancarios.

Si a lo anterior unimos la creencia en la autorregulación eficiente de los mercados financieros, la consecuencia es el predominio de un «pensamiento de grupo», compartido entre supervisados y supervisores, que no advierte el creciente nivel de riesgo que se deriva de la concentración de crédito en el sector inmobiliario. Un primer problema detectado en los procedimientos supervisores es que las personas que expresaron opiniones críticas y advirtieron argumentadamente del aumento en el nivel de riesgo, finalmente perdieron su trabajo, se vieron relegados o perdieron reputación.

Un segundo problema, relacionado con el anterior, fue que la confianza excesiva en la eficiencia del mercado condujo también a debilitar el gobierno interno de las entidades; una serie de funciones esenciales de control no existían realmente en algunas entidades, o estaban insuficientemente dotadas.

En el caso de los auditores, que tienen a su alcance, al menos en teoría, vías efectivas para advertir tanto a los órganos de gobierno de las entidades, como al mercado y al supervisor, el problema parece residir en un apego al historial de 
resultados pasados, sin añadir un juicio sobre la sostenibilidad del modelo de negocio y a la pérdida de calidad del gobierno y control interno.

En el caso de las autoridades de regulación y supervisión, no parece apreciarse, en la experiencia de Irlanda, una insuficiencia de competencias o poderes, sino más bien un juicio complaciente y una minusvaloración del riesgo, tanto el intrínseco de cada entidad como el sistémico. No hay evidencia de que el supervisor hubiera expresado advertencias o juicios críticos previamente a la crisis; lo que se aprecia es que las pocas personas que expresaron juicios discrepantes en los órganos de dirección no consiguieron convencer a los órganos de gobierno o a sus superiores (CIBSI, 2011, pág. vii).

De todos los informes sobre la reforma del sistema financiero, destacan como hemos visto una serie de rasgos comunes. El primero de ellos es la necesidad de que los órganos de supervisión y control mantengan un espíritu crítico permanente en el análisis del nivel de riesgo asumido por las entidades, y sepan decir «no» en el momento en que una entidad haya rebasado el umbral crítico (Viñals y Fietcher, 2010).

El segundo sería la necesidad de mejorar los mecanismos de gobernanza de las entidades, para prevenir conflictos de intereses, evitar esquemas retributivos inadecuados, que incentiven una excesiva asunción de riesgos o dedicar recursos insuficientes a las funciones de control interno. Un tercer aspecto sería el conceder una mayor importancia al riesgo sistémico, dado que en el sistema financiero los problemas de una entidad se trasladan con gran rapidez a la totalidad del sistema, poniendo en peligro la continuidad de los sistemas de pago, secando los mercados de liquidez y minando la confianza de los depositantes.

Una puntualización adicional de interés es la de subrayar la importancia de las alertas e intervenciones tempranas, por el alto riesgo de contagio que suponen las crisis financieras (tanto entre las entidades del sistema, como del sistema financiero al resto de la economía y el riesgo soberano). Dado el tamaño global del sistema financiero, que en la eurozona supone el 250 por 100 del PIB, el problema puede ir más allá del riesgo moral que supone un sector demasiado grande para quebrar (too big to fail), puesto que el problema, en muchos países es que puede convertirse en un sector demasiado grande para ser rescatado (too big to be saved) por el Sector Público nacional (Gros, 2013).

Ante los problemas planteados por la crisis financiera, las reformas se han planteado en una doble dirección.

Por un lado, para mejorar la regulación global sobre solvencia, ante la constatación de que ciertos elementos de capital no eran útiles, para mantener la solvencia de una entidad en funcionamiento (los elementos de capital que pueden 
emplearse en una entidad en liquidación, suponen ya un cierto fracaso de las medidas supervisoras).

Con esta orientación, el acuerdo alcanzado en el Banco Internacional de Pagos de Basilea (BIS), para reforzar la calidad de los elementos de capital y aplicar gradualmente un aumento de los requerimientos de capital, en la línea de reforzar la solvencia y reducir la prociclicidad de la regulación de Basilea II, supuso un primer paso (BIS, 2011). El último informe sobre la implantación de Basilea III, con datos de los principales bancos, indica que la reforma avanza a buen ritmo (BIS, 2015).

En la UE, estas iniciativas de reforma han cristalizado en la Directiva 2013/36/UE del Parlamento Europeo y del Consejo, relativa al acceso a la actividad de las entidades de crédito y su supervisión prudencial y en el Reglamento UE núm. 575/2013, de 26 de junio de 2013, sobre requisitos prudenciales de las entidades de crédito y empresas de servicios de inversión y en España, en la Ley 10/2014, de 26 de junio, sobre ordenación, supervisión y solvencia de las entidades de crédito.

Estos nuevos y mayores requerimientos de capital requieren un cierto período hasta su plena implementación, dada la distinta posición inicial de los bancos europeos, en materia de solvencia (Schoenmaker y Peek, 2014).

Una segunda línea de reforma ha ido en la dirección de reforzar las competencias de los bancos centrales, en su función de supervisores del sistema financiero, así como lograr una mayor homogeneidad en las tareas supervisoras, dentro de la Unión Europea. Desde esta perspectiva, la crisis financiera originó también un nuevo diseño normativo y de control, que empezó de forma inconexa, hasta avanzar paulatinamente hacia la Unión Bancaria en la Unión Europea, con su Mecanismo Único de Supervisión, Mecanismo Único de Resolución y Fondo de Garantía Europeo. Concretamente, el Reglamento BCE/2014/17, por el que se establece el marco de cooperación en el Mecanismo Único de Supervisión entre el BCE y las autoridades nacionales competentes (Reglamento Marco del MUS) supone un paso fundamental en el camino hacia la Unión Bancaria en la UE, al aplicar por primera vez un esquema supervisor homogéneo a todas las entidades financieras definidas como significativas, a nivel de la UE.

Hay que mencionar también que, al comienzo de la crisis, los poderes de los supervisores financieros variaban ampliamente de unos países a otros, especialmente en lo que se refiere a los supuestos para intervenir una entidad, la cuantía de las sanciones pecuniarias y el hecho de que éstas pudieran imponerse a las personas físicas, además de a las entidades (CEBS, 2009, págs. 4-5).

En el caso de España, el apartado 24 del MoU establece la necesidad de mejorar la independencia operativa y las competencias sancionadoras del BdE. 
Una de las medidas adoptadas para mejorar la eficiencia de los mecanismos de supervisión fue la ya citada de potenciar las competencias sancionadoras del BdE, implementada en la Ley 10/2014, que mejora lo que podríamos llamar su eficiencia externa.

En paralelo, también se adoptaron medidas para perfeccionar los métodos de supervisión de BdE, y en concreto, «a fin de cerciorarse de que las conclusiones de las inspecciones realizadas in situ se traducen, rápida y eficazmente, en medidas correctivas» (MoU, 2012, apartado 24). En este mismo sentido, el informe de la Comisión Interna de BdE creado para reformar los procedimientos supervisores, alude a una circular interna que introduce dos novedades relevantes:

«a) que las conclusiones de las visitas de inspección se trasladen con rapidez a los órganos decisorios, concretamente que no pasen más de 60 días desde que se firma el informe de inspección, hasta que el Director General eleva la correspondiente propuesta a la Comisión Ejecutiva (art. 18); b) que, en el caso de que existan discrepancias entre el responsable de la elaboración del informe y el jefe de grupo, el Director General informe a la Comisión Ejecutiva sobre esta circunstancia (art. 10)» (Banco de España, 2012, pág. 14).

La anterior es una muestra de que el peligro de la «captura del regulador/ supervisor» por la industria debe contemplarse explícitamente, impidiendo que consideraciones de «ayuda a la industria financiera nacional» se traduzcan en conclusiones más laxas de los informes supervisores, en que los escalones superiores suavicen las conclusiones de quienes actúan en la primera línea de supervisión.

En la revisión de las causas que llevaron a la crisis financiera internacional, las presiones políticas y del mercado sobre los supervisores se han citado como uno de los factores desencadenantes (Palmer y Cerruti, 2009, págs. 10-12). Otro gran experto en el funcionamiento real de los sistemas de supervisión, Raimundo Poveda, cita las cesiones a las exigencias de la industria como uno de los factores que llevaron a desvirtuar Basilea II y advierte que «ya se sabe que todo supervisor acaba contaminado por las ideas de sus supervisados y los supervisores bancarios no son una excepción» (Poveda, 2011, pág. 48).

Un gran interrogante que se abre, teniendo en cuanta los problemas de captura del supervisor, es en qué medida las deficiencias observadas en la supervisión se deben a la carencia de mayores competencias de sanción o a la inadecuada utilización de las existentes, aspecto éste que veremos en el apartado siguiente, al analizar el papel de los datos, como base para la supervisión y la toma de decisiones. 


\section{LAS LECCIONES DE LA EXPERIENCIA COMPARADA}

Una primera enseñanza que puede extraerse de las reformas supervisoras emprendidas en el sector financiero es la de prestar atención a la delimitación cuidadosa del ámbito de control, que incluye no solamente cuáles son los organismos y entidades que forman parte del perímetro de control (asunto éste que, para las Administraciones Públicas, contemplan de modo expreso en la Unión Europea las normas de Eurostat y el Protocolo de Déficit Excesivo), sino también qué tipo de actividades deben ser revisadas de modo prioritario y con qué periodicidad.

La experiencia demuestra, tanto en el sector financiero como en el sector público, que los principales riesgos para las actividades de control se encuentran en la proliferación de entidades que se sitúan al margen del control y la supervisión; es el conocido como sector público extrapresupuestario (Off-Budget Public Sector), sobre el que alerta el trabajo ya clásico de Bennett y Di Lorenzo (1983) o la banca en la sombra (Shadow Banking), sobre la que llama la atención tanto el informe Turner, sobre la reforma del sector financiero (Turner, 2009, págs. 70-73), como el informe Larossière (Larossière, 2009, pág. 8) y otros trabajos (Gieve, 2009, pág. 7).

En este punto, es importante subrayar que la atención a las normas de gobierno interno de las entidades supervisadas es un aspecto crucial para evitar que se produzcan posteriormente problemas de eficiencia.

Una segunda enseñanza que surge de las medidas de reforma en el sistema financiero es la de potenciar los mecanismos de alerta temprana y, especialmente, que el organismo supervisor y de control pueda activarlos de modo eficaz. Como ejemplos de medidas aplicadas en el sistema financiero que podría pensar en extenderse al ámbito del Sector Público, está el considerar la posibilidad de incidir en aquellos aspectos de la programación o gestión presupuestaria que han mostrado repetidamente su ineficacia (o el ser una fuente de conflictos de intereses o incentivos perversos).

En concreto, del mismo modo que el BdE y la CNMV están habilitados para emitir circulares que regulen materias concretas del sector bancario o los mercados de valores, siempre dentro del marco normativo general y con habilitación expresa, podría pensarse en un mecanismo semejante, que pudiera ser activado o utilizado por los OCEx, de modo que pudiera actuarse con rapidez sobre aquellas disfunciones de gestión presupuestaria y del gasto que se observen repetidamente por los órganos de control.

Evidentemente, ésta es una materia delicada, en la cual debemos movernos entre el respeto al ámbito legítimo de actuación que deben tener los gestores, 
sean éstos financieros o presupuestarios y el respeto a la jerarquía normativa, pero evitando que el resultado de las actividades de control sea ineficaz por tardío, cuando se observa repetidamente y con argumentos sólidos que un determinado hueco o disfunción regulatoria es el origen de problemas repetidos de control.

Un tercer aspecto a considerar es el del tratamiento de los datos que constituyen la base de toda actividad de control.

El principal aspecto a destacar aquí, respecto a las enseñanzas que ha ofrecido la crisis en el sistema financiero, es que no ha sido la carencia de datos o la falta de calidad de éstos el factor desencadenante de los mayores errores en la supervisión financiera, sino lo que podríamos llamar la carencia del «valor moral de decidir», es decir, la ausencia de la toma de decisiones por parte de los órganos de gobierno de los supervisores financieros.

Este hecho, que es certeramente destacado en el informe sobre la crisis financiera en Irlanda, se debe a los defectos del «pensamiento de grupo», a no tener en cuenta a las voces críticas, que no son escuchadas (o en ocasiones, incluso son acalladas) y al hecho de refugiarse en una «estrategia defensiva de control», en la cual se solicitan de modo continuo más datos, que nunca son suficientes y que encubren, en muchos casos, el temor a arrostrar las consecuencias de las decisiones difíciles (6) en una buena muestra de que no se ha llegado a completar el aprendizaje de saber decir no en el momento adecuado (Viñals y Fietcher, 2009), por falta de coraje moral.

Éste es un hecho repetido, que podemos comprobar que aparece recurrentemente en las crisis financieras graves y que ya expresó con claridad Luis Ángel Rojo, entonces Gobernador del BdE, en su comparecencia ante el Congreso de los Diputados, para explicar, en 1993, la intervención de Banesto, cuando señalaba que «cualquiera que sea el momento en que se intervenga a un banco en graves dificultades, siempre habrá quien diga que se ha actuado demasiado pronto y siempre habrá quienes piensen que se ha actuado demasiado tarde; el banco central quedará, en todo caso, sometido a críticas y se verá envuelto en polémicas con fuertes componentes políticos» (Rojo, 1994, pág. 473).

Finalmente, debemos referirnos al espinoso tema de definir cuántos datos son necesarios y cuáles deben de ser las repercusiones de la negativa a suministrar información o la entrega de información gravemente deficiente, por parte de los supervisados.

(6) Existe evidencia empírica que muestra que en algunos países, como es el caso de Alemania, esta tendencia del supervisor a retrasar decisiones difíciles no se ha dado (Kick, Koetter y Poghosyan, 2010). 
Destacar aquí que, en el sector financiero, ésta es una cuestión resuelta de forma tajante, tanto en la anterior Ley 16/1988, de Disciplina e Intervención de Entidades de Crédito (arts. 4 y 5), como en la reciente Ley 10/2014 (arts. 92 y 93); la negativa a proporcionar información o la información inexacta son catalogadas como infracciones graves o muy graves, para las entidades de crédito y pueden dar lugar nada menos que a la destitución de los miembros del Consejo de Administración, a la sustitución del personal de la alta dirección y a la intervención de la entidad.

Ante medidas de calado tan hondo, que aplican los poderes públicos cuando ejercen la supervisión financiera sobre entidades privadas, merece al menos una reflexión si no deberían introducirse mecanismos equiparables cuando la negativa o las deficiencias en el suministro de datos se producen en el seno del propio Sector Público.

Relacionado con lo anterior está el siempre delicado tema de cómo se transmite la información en el seno de los órganos de control y supervisión y, en última instancia, de qué mecanismos existen para asegurar la integridad de las decisiones.

Dado que en los procedimientos de supervisión y control existe normalmente una separación entre quienes ejercen directamente las actividades de control y actúan sobre el terreno, obteniendo la información, revisándola y haciendo un diagnóstico de la situación (que incluye normalmente identificar carencias y proponer medidas correctoras) y quienes toman la decisión final, que son los órganos de gobierno del más alto nivel, debe plantearse la pregunta legítima de cómo se relaciona todo el proceso. En concreto, la experiencia del sistema financiero muestra que existe un peligro potencial debido a la existencia de escalones intermedios o filtros que pueden hacer que la información y las propuestas de los grupos de inspección que actúan sobre el terreno no queden debidamente reflejadas en las propuestas que recibe la Comisión Ejecutiva del BdE.

Otro aspecto en el que han incidido de modo muy notable las reformas en el sistema financiero ha sido el de la mejora de los procedimientos de gobierno interno, para evitar conflictos de intereses, incentivos perversos o no explicitar problemas de incompatibilidades.

Concretamente, tanto los artículos 88, 91 y 92 de la Directiva 2013/36/ UE, sobre acceso a la actividad de entidades de crédito y su supervisión prudencial, como los artículos 24, 25, 26 y 28 de la Ley 10/2014, de 26 de junio, de ordenación, supervisión y solvencia de las entidades de crédito, destacan la importancia de una adecuada selección de los miembros de los órganos de gobierno de las entidades financieras, que deben ser evaluados por una unidad independiente que analice si: 
1. Tienen una formación adecuada para el perfil del puesto a desempeñar.

2. ${ }^{\circ} \quad$ Poseen experiencia práctica suficiente en el desempeño de puestos de responsabilidad, durante tiempo suficiente, en puestos de un nivel similar de responsabilidad (a los puestos más elevados de decisión, en el sector financiero y en los órganos de control, no debería llegarse a aprender, sino con la experiencia suficiente para desempeñar tal responsabilidad de forma plena, desde el primer momento) (7).

3. ${ }^{\circ}$ Puedan acreditar honorabilidad personal y profesional, no estando condenados ni incursos en procedimientos investigadores por temas fiscales, mercantiles o administrativos.

4. ${ }^{\circ}$ Ausencia de conflictos de intereses, debido a los puestos anteriormente desempeñados, por participación en empresas o sociedades mercantiles, personalmente o de familiares directos.

Si en el Sector Público se aplicara internamente un principio de simetría y exigiera a los miembros de los órganos de supervisión y control de todo tipo las mismas reglas — que parece un principio razonable_- debería analizar, previamente al nombramiento de sus miembros, tanto su formación y experiencia en puestos anteriores de nivel similar, como la independencia formal y real respecto al ejecutivo, partidos políticos y otros entes sujetos a fiscalización, para evitar los posibles conflictos de intereses.

En el supuesto de que las actividades de supervisión y control detecten irregularidades graves, las medidas correctivas o, en último extremo, de intervención de la entidad, tienen aparejado, en el sistema financiero, la cautela para que los intereses esenciales de terceros que se relacionen con la entidad que presenta las deficiencias queden salvaguardados. A este motivo responden las coberturas ofrecidas por los Fondos de Garantía de Depósitos en Entidades de Crédito (FGDEC), que fueron elevados al inicio de la crisis financiera, cubriendo actualmente el importe de $100.000 €$ por depositante y entidad y la previsión de que la posible intervención de una entidad contemple la salvaguardia de continuidad en los mecanismos de pago e intermediación financiera a su cargo, para evitar graves perturbaciones en la economía nacional.

En el caso del control del Sector Público, las deficiencias observadas en el funcionamiento de aquellas AAPP que prestan servicios esenciales podrían incorporar la posibilidad de exigir actuaciones inmediatas para la mejora del

(7) La carencia de un conocimiento práctico suficiente sobre el funcionamiento del sector supervisado se ha mencionado como uno de los factores que han contribuido a la crisis. Véase Palmer y Cerruti (2009), págs. 15-16.

Revista Española de Derecho Constitucional

ISSN-L: 0211-5743, núm. 105, septiembre-diciembre (2015), págs. 51-76

http://dx.doi.org/10.18042/cepc/redc. 105.02 
servicio, de modo que los intereses de los usuarios se contemplaran de modo adecuado.

Finalmente, habría que señalar que un buen mecanismo de supervisión y control debe de ser proactivo y plantearse como exigencia, cada vez que se lleva a cabo una reforma, cuáles pueden ser las respuestas más amplias del sector privado y las reacciones más probables de los supervisados. Se trata de evitar así que medidas bienintencionadas, que tratan de atajar un problema, no acaben generando otro de mayor dimensión, por no prestar atención al nuevo marco de incentivos (8).

En la estrategia de reforma de la supervisión, para hacer frente a la crisis financiera, pueden señalarse algunos defectos del tipo apuntado, como serían:

1. ${ }^{\circ}$ Agravamiento del «too big to fail», al propiciar la concentración de entidades, lo cual, según muestra el caso de Italia, puede dar lugar probablemente a problemas de menor competencia y mayor coste de los servicios financieros, además de la posible exclusión financiera en las zonas de baja densidad de población (Ayadi, Schmidt y Carbó, 2010, págs. 168-172). El que algunas Cajas de Ahorros en España hayan sido mal gestionadas y sufrido problemas de solvencia, no puede llevar a condenar este modelo de entidad, que contribuye a fomentar la competencia y juega un importante papel para evitar la exclusión financiera.

2. ${ }^{\circ} \quad$ Volver a caer en los defectos señalados previamente y que han sido el origen de la crisis. En este sentido, pese a la señalada falta de profesionalidad de los órganos de gobierno de las Cajas de Ahorros en España, que han propiciado a la deficiente gestión de riesgos en algunas entidades y, en último extremo, al deterioro de su solvencia y la necesidad de intervención, de forma inexplicable la Ley 26/2013 de cajas de ahorros y fundaciones bancarias vuelve a recaer en este defecto.

Si observamos el papel de accionistas de referencia de las fundaciones bancarias en algunas de las entidades financieras más relevantes del país y el hecho de que, aunque las nuevas fundaciones bancarias hayan perdido la condición de entidades financieras, los miembros de su Patronato tienen importantes obligaciones de suministro de información y relaciones con el BdE, estando sujetos a la Ley de Disciplina e Intervención (9) (con lo cual, pueden ser multados con

(8) Damos por supuesto que los mecanismos de reforma han sido diseñados de modo adecuado y son coherentes con la naturaleza del problema a tratar, según sea éste de tipo distributivo o de eficiencia.

(9) En este momento, la referencia debe entenderse a la Ley 10/2014, de ordenación, supervisión y solvencia de las entidades de crédito. 
5.000.000 de $€$ e inhabilitados para ocupar cargos en el sector financiero, en caso de infracción muy grave, o multa de $250.000 €$ e inhabilitación por cinco años para ocupar cargo de dirección en la misma entidad, si la infracción es grave), podemos constatar que es necesario crear los incentivos adecuados para que los miembros del Patronato cuenten con experiencia financiera y dediquen tiempo suficiente a sus funciones.

Pese a lo anterior, se prevé, sin embargo, que «los patronos ejercerán su cargo gratuitamente» (art. 40.4 de la Ley 26/2013).

Este supuesto de conseguir el logro de la excelencia a coste cero parece incongruente con la constatación de que la falta de profesionalidad de los miembros de los órganos de control interno y un esquema retributivo inadecuado fue uno de los orígenes de la crisis de las Cajas de Ahorros (Serra, 2011, págs. 92-99).

La posibilidad de cobrar por otro tipo de servicios, distintos al desempeño de las funciones de patrono tiene el inconveniente de que puede abrir la puerta a conflictos de intereses, además de la incongruencia de que los patronos tengan asignadas funciones de importante responsabilidad, por las que no cobran, para luego permitirles cobrar por funciones distintas y no muy claras.

Lo más razonable sería haber planteado un esquema retributivo ajustado a las características y responsabilidades del puesto a desempeñar, máxime para aquellos miembros del Patronato que sean especialistas en temas financieros, para los cuales van a exigirse los mismos requisitos de idoneidad que a los miembros de órganos de gobierno de entidades financieras [arts. 17.2, 39.3.e) y 40.2 de la Ley 26/2013].

\section{CONCLUSIONES}

La crisis financiera, iniciada en septiembre de 2008, ha ido en paralelo con los problemas de endeudamiento y déficit del Sector Público. Ambos procesos se han influenciado, puesto que el importante volumen de fondos públicos que se ha inyectado para apoyar a los bancos en reestructuración ha sido una de las causas del aumento del déficit y el endeudamiento.

Durante este proceso, la crisis financiera se ha desarrollado con más rapidez que la del Sector Público, y para remediarla se han ensayado diversas estrategias de reforma, que han cristalizado en el paquete de reforma conocido como Basilea III, que ha ido en la dirección de reforzar el capital y los mecanismos de gobierno interno de las entidades financieras, para evitar un comportamiento procíclico del flujo de crédito. 
De las lecciones de la experiencia comparada que podemos observar en la crisis financiera, hay algunas que resultan especialmente útiles para mejorar el control de eficiencia del Sector Público. La primera de ellas sería que, además de los resultados que podemos observar en los programas de gasto público, importa también el procedimiento por el que se obtienen dichos resultados.

Los mecanismos de toma de decisiones que garantizan la independencia de los supervisores y evitan su captura por los supervisados/controlados son un ingrediente esencial para un buen control de eficiencia.

Velar por la idoneidad de quienes ocupan funciones clave y gestionar adecuadamente los conflictos de intereses debe ser parte esencial del control de eficiencia, puesto que las reglas de decisión influyen en los resultados.

Otra importante enseñanza de la crisis financiera es la de potenciar los mecanismos de alerta temprana y conceder a los supervisores/controladores mecanismos operativos, para requerir que se introduzcan mejoras, cuando las deficiencias son graves. El notable aumento de competencias supervisoras y sancionadoras concedido a los supervisores financieros puede ser motivo de reflexión, para ver si convendría implementar alguna medida semejante en el campo del control del Sector Público.

También es necesario destacar que en la reforma del sistema financiero ha habido una importante preocupación por la situación tanto del depositante - ampliando el límite de los depósitos cubiertos por el FGDEC y garantizando su percepción en breve espacio de tiempo- como del cliente, para mantener la continuidad y seguridad de las operaciones y sistemas de pago. Una preocupación semejante no parece existir en el Sector Público, donde las deficiencias apreciadas por los órganos de control no suelen ir seguidas de recomendaciones para restablecer la necesaria calidad de los servicios públicos esenciales, que pueden haberse deteriorado a consecuencia de las deficiencias de gestión detectadas.

Finalmente, otro aspecto a destacar es la necesidad de analizar en profundidad las consecuencias de las reformas decididas, puesto que frecuentemente una reforma pensada para paliar un problema contiene entre sus medidas, pensadas exclusivamente con esa óptica, el germen de nuevos problemas, que aparecerán en el futuro. Tener en cuenta las respuestas del sector privado y evitar la creación de incentivos perversos es el modo más adecuado de proceder, en este punto.

Revista Española de Derecho Constitucional 


\section{BIBLIOGRAFÍA}

AYADI, Rym; SCHMIDT, Reinhard, y CARBÓ, Santiago (2008): Investigating Diversity in the Banking Sector in Europe. The Performance and Role of Savings Banks, Brussels, CEPS.

BANCO DE ESPAÑA (2012): Análisis de los procedimientos supervisores del Banco de España y recomendaciones de reforma. MoU FSPC - Informe de la Comisión Interna, Madrid, Banco de España.

- (2014): Nota informativa sobre ayudas públicas en el proceso de restructuración del sistema bancario español (2009-2013), Madrid, Banco de España.

- (2015): Nota informativa sobre ayudas públicas en el proceso de reestructuración del sistema bancario español (2009-2015), Madrid, Banco de España.

BennetT, James, y Di LoREnzo, Thomas (1983): Underground Government: The OffBudget Public Sector, Washington, Cato Institute.

Bank of International Settlements (2011): Basel III. A global regulatory framework for more resilient banks and banking systems, Basilea, BIS.

- (2015): Basel III Monitoring Report. September 2015, Basilea, BIS.

CÁmARA de Comptos de NAVARRA (2014): Actuación del Gobierno de Navarra en el ejercicio de sus funciones inspectoras y de protectorado sobre la Caja de Ahorros de Navarra (1982-2011), Pamplona, Cámara de Comptos de Navarra.

COMMITTEE of EuROPEAN BANKING SuPERVISORS (2009): Mapping of supervisory powers, including early intervention measures and sanctioning powers, Review Panel 2009, Londres, CEBS.

CiHAK, Martin, y TIEMAN, Alexander F. (2008): Quality of Financial Sector Regulation and Supervision Around the World, IMF Working Paper/08/190, Washington, FMI.

COMMISSION OF INVESTIGATION INTO THE BAKING SECTOR IN IRELAND (2011): Misjudging risk: Causes of the Systemic Banking Crisis in Ireland.

FROB (2014): Comparecencia del Presidente de la Comisión Rectora del FROB en la Comisión de Economía y Competitividad del Congreso de los Diputados.

Furceri, Davide, y Mourougane, Annabelle (2009): Financial Crisis: Past Lessons and Policy Implications, OECD, Economics Department, Working Papers núm. 668, París, OCDE.

GIEVE, John (2009): Seven lessons from the last three years, London, London School of Economics.

Gros, Daniel (2013): What's wrong with Europe's Banks, CEPS Commentary, Bruselas, Center for European Policy Studies.

KICK, Thomas; Koetter, Michael, y Poghosyan, Tigran (2010): Recovery Determinants of Distressed Banks: Regulators, Market discipline or the Environment?, FMI Working Paper 10/27, Washington, FMI.

LAROSSIÈRE, Jacques de (Larossière Group) (2009): The High Level Group on Financial Supervision in the EU, Bruselas.

Revista Española de Derecho Constitucional

ISSN-L: 0211-5743, núm. 105, septiembre-diciembre (2015), págs. 51-76

http://dx.doi.org/10.18042/cepc/redc. 105.02 
MAUdos, Joaquín (2011): El sector bancario español en el contexto internacional: el impacto de la crisis, Madrid, FUNCAS.

MEMORANDUM OF UndeRSTANDING (MoU) (2012): Memorandum of Understanding on Financial-Sector Policy Condicionality.

PALMER, John, y CERRUTI, Caroline (2009): In there a need to rethink the supervisory process?, discussion paper, Conference of World bank and Bank of Spain on «Reforming financial Regulation and supervision; Going Back to Basics»».

PovedA, Raimundo (2011): «De Basilea I a Basilea III», Perspectivas del Sistema Financiero, núm. 102, págs. 47-69.

ReInHardt, Carmen M., y Rogoff, Kenneth S. (2011): This Time is Different. Eight Centuries of Financial Folly, Princeton, New Jersey, Princeton University Press.

RoJo, Luis A. (1994): «Reflexiones sobre la supervisión bancaria y la intervención del Banco Español de crédito», en A. Rojo, Discursos y Conferencias, Madrid, Banco de España, págs. 463-473.

- (2012): Discursos y conferencias, Madrid, Banco de España.

Schoenmaker, Dirk, y PeEk, Toon (2014): The State of the Banking Sector in Europe, OECD Economics Department Working Papers, núm. 1102, París, OCDE.

SERRA, Antoni (2011): Los errores de las Cajas. Adiós al modelo de las cajas de ahorros, Barcelona, Ediciones Invisibles.

Tribunal de Cuentas (2013a): Informe de fiscalización del Fondo de Adquisición de Activos Financieros, Informe núm. 989, Madrid, Tribunal de Cuentas.

- (2013b): Informe de fiscalización de la legalidad de las actuaciones del Fondo de Reestructuración Ordenada Bancaria, de los Fondos de Garantía de Depósitos y del Banco de España, relacionadas con la reestructuración bancaria, referida al período 2009-2012, Informe núm. 1029, Madrid, Tribunal de Cuentas.

TRIBUnal de Cuentas EuRopeo (2011): Consecuencias de la actual crisis económica y financiera en la rendición de cuentas y la fiscalización del sector público en la UE y la función del TCE: documento de posición del TCE, Luxemburgo, TCE.

TURNER, Adair (2009): The Turner Review: a regulatory response to the global banking crisis, London, Financial Services Authority.

VIÑALS, José, y FIETCHER, Jonathan (2010): The Making of Good Supervision: Learning to Say «No», IMF Staff Position Note, Washington, FMI.

Revista Española de Derecho Constitucional 